\title{
Geriatrics and Longevity Sciences in Japan
}

The average life span of Japanese people has been expanding with tremendous rapidity; faster than a developed country has ever experienced. It has become the country with the longest life expectancy in the world with an average life span of 83.59 years for females and 77.01 years for males, according to the 1996 statistics by the Ministry of Health and Welfare. The time span for the increase in the percentage of elderly (beyond 65 years) to the whole population from 7\% (1968) to 14\% (1992) was only 24 years for Japan, whereas it took 130 years in France, 85 in Sweden, 50 in England and 45 years in Germany. It is expected to reach $25 \%$ in 2,025 in Japan.

Japan has long enjoyed a reputation for its ideal health insurance system. Medical expenses are completely covered by public medical insurance with little to no payment by patients; therefore, no one should ever suffer from inability to receive medical services because of economical reasons. Now Japan faces a turning point in national policies on medical and welfare services because of the following conditions:

1) The increase in population of elderly subjects. In Japan, most businessman work at only one company or its affiliated institution, and retirement from job is determined by a traditional rule of economical societies, and is below 60 years of age in most instances.

2) Medical expenses for elderly people have increased rapidly in the last decade.

3) The decrease in child birth over the last decade was very marked, and labor power is expected to decrease in the first half of the 21 st century. For these reasons, it is extremely urgent for Japan to establish a new society where elderly people engage in productive activity in cooperation with the younger generation.

\section{History of Gerontology in Japan}

In 1959, the Japan Gerontological Society was founded by Japan Geriatrics Society and Japan Socio-gerontological Society. Since then, a department of geriatric medicine has been established in many medical schools, and institutes of aging or geriatrics have been established in several universities as well. Aside from medical schools or universities, two institutes on aging, The Tokyo Metropolitan Institute of Gerontology (TMIG) and The National Institute for Longevity Sciences (NILS) have been growing in their activities, and now have become two major centers for geriatrics in Japan. In 1978, The 11th World Congress of Gerontology was held in Tokyo which promoted research and medical practice. Now the Japan Gerontological Society has 8,000 members in clinical, basic and social gerontology (1).

\section{Government Projects in Gerontology}

In 1986, "The National Strategy for the Decade for the Aged - Gold Plan" was proposed by the Japanese Government in commemoration of 60 years of reign of Emperor Showa. In the field of medicine, this project consisted of establishment of geriatric hospitals and nursing homes, promotion of education and training of nurses, home helpers and coordinators for medical and social cares for the aged. Furthermore, medical insurances, social welfare, housing, pension and other economical problems have all been included in this study covered by this national plan. For the promotion of the national project, a special agency for longevity sciences (Choju Kagaku Shinko Zaidan) was established. The research fields of longevity sciences of this agency are categorized into six: 1) basic research on aging, 2) geriatric medicine, 3) rehabilitation, nursing and care, 4) development of support- and substitution instruments, 5) social sciences, and 6) oriental medicine (2).

In 1997, the NILS was established in affiliation with National Chubu Hospital. It is expected to become one of the major National Institutes of Medicine in Japan in the near future. The institute consists of eight departments: Department of Basic Gerontology, Department of Molecular Genetic Research, Department of Epidemiology, Department of Dementia Research, Department of Geriatric Research, Department of Biofunctional Research, Department for the Care of the Aged, and Department for Development of Supporting Equipment.

The institute has been growing rapidly in its activity with sixty research scientists (permanent and temporary working staff) and sufficient funds mainly from the government. The Science Council of Japan, which functions as an advisory organization for the Prime Minister of Japan for national science projects, published a special committee report on "Quality of life and purpose of living for the aged from medical and social aspects" in 1997, and proposed various policies in the society with the aged from medical, psychological and sociological aspects in the coming decade. With the declaration of the decade of brain research in Japan, the government proposed "the science promotion act", to the parliament in 1996, and increase in the budget for science research was doubled in 1997 compared to that of the previous year. In 1997, the basic research fund for comprehensive longevity sciences from the Ministry of Health and Welfare amounted to 1,833 million yen (15 million US dollars) and 9,541 million yen for advanced research fields in Health and Welfare Research were newly expanded, including 1,500 million for brain science research. This strong financial support is expected to promote research in 
medicine and care for the elderly in Japan (3).

\section{Cultural and Economical Backgrounds of Elderly Care in Japan}

In Japan, there has been a traditional custom of taking care of the old people at individual homes, paying very high respect to the old, primarily because of the influence of traditional Confucianism. Accordingly, it had been regarded as a natural and respective way for every member of a family to respect and to take care of the older generation. However, we are now facing a totally new social situation where taking care of the elderly is beyond the capability of each individual or the family members because of two reasons. First, drastic changes after World War II in social structure resulted in the increase in one generation families rather than the traditional two generation families with many family members. Second, as the generations that really should be cared for are in their eighth decade, the next generation which are expected to support the former are already older than 60 years of age and are already in retirement and can not support their parents from the viewpoint of both physical and economical conditions.

As the above conditions have lasted for more than fifty years, the housing problem really does not allow a big family of three generations to live together. Together with other socio-economical reasons, establishment of a new society is urgently needed where old populations live with social responsibilities and engage in productive works and live in harmony with younger populations. It has to be done with primary responsibility of the society itself rather than of individuals. Research in this fields are mandatory.

\section{Geriatrics in Japan}

Research in geriatrics in Japan is not outstandingly unique nor exceptional in the world. Dementia has been a major topic and studies include etiology, molecular genetics of Alzheimer's disease, epidemiology, pathophysiology and treatment of dementia of various etiology. Atherosclerosis, osteoporosis and rheumatoid arthritis are three other major topics which the government focuses studies. The agency for longevity sciences has conducted a series of silver science research since 1988 with researchers from all over Japan and annual reports have been published. Topics of studies were partly modified for the last ten years and they are as follows (2).

1. Special pathological conditions relating to aging. These include neuro-muscular functions of the elderly, prevention and treatment of senile osteoporosis, epidemiology of senile cataract, prevention and treatment of dental disease of the aged, indication of surgery for the aged, and others.

2. Studies on mechanisms of aging.

1) Glycolipids changes in metabolism by aging and expression of age-related gene.

2) Atherosclerosis inducing substances in the environment and their mechanisms of action.

3) Effects of growth hormones on aging.

3. Promotion of health and epidemiology research.

1) Health evaluation in order to promote health of the aged.

2) Prediction of needs of the aged in the future society.

3) Development for health and strength maintenance and their promotion system for the aged.

4) Nutrition control plan throughout life in relation to research on aging protection effects of food components.

4. Home health care, medical technology, nursing and rehabilitation.

1) Nursing and rehabilitation research for home health care from the viewpoint of disease conditions of the aged.

2) Comprehensive research on drug therapies for the aged.

3) Development of personal health document recording system for health control of the aged.

5. Development of the silver health care support system.

Sixteen research projects are underway for information acquisition, development of instruments for functional recovery or substitution, environment maintenance for the aged or handicapped-aged. These research projects have been carried out with project teams composed of researchers in medicine, engineering, statistics, economy and related fields.

A completely new comprehensive medico-social insurance system for the aged over 65 years is planned to start in the year 2,000 . It will cover medical treatment and care, living in healthy condition with high quality of life for the elderly people in health or disease. Resources will be from the government, local governments and individual recipients, and the local governments will be in charge of operation. Education and training of staff in various functions, building of nursing homes and supply of beds for this system are mandatory.

Nobuo Yanagisawa, MD, PhD President, Natıonal Chubu Hospital and Natıonal Institute for Longevity Sciences

Gengo 36, Morıokamachı, Ohbu 474

\section{References}

1) Special issue Recent progress in gerontology research in Japan Arch Geront Geriat 19: 89, 1994.

2) Life Style of the Elderly Person and Longevity Sciences Sobue I, Ed Longevity Science Promotion Agency, Tokyo, 1991 (in Japanese)

3) White papers on Health and Welfare Ministry of Health and Welfare, Ed 1996 editıon, Koseımondaı Kenkyukaı, Tokyo, 1997 